\title{
Cyclosporine A Loaded Nanoemulsions using Bio-oil Fractions of Sesame Oil
}

\author{
Samir Bhargava ${ }^{1,2, *}$, NV Satheesh Madhav ${ }^{1}$ \\ ${ }^{1}$ DIT-Faculty of Pharmacy, DIT University, Dehradun, Uttarakhand, INDIA. \\ ${ }^{2}$ Faculty of Pharmacy, Uttarakhand Technical University, Dehradun, Uttarakhand, INDIA.
}

\begin{abstract}
Title: Cyclosporine A loaded Nanoemulsions using Bio-oil Fractions of Sesame Oil. Aim: Nanoemulsions formulation development is an upcoming approach to deliver peptides. The approach reduces challenges during peptide delivery by many folds. Nanoemulsions contains drugs encapsulated or solubilized in an oily phase, with water as continuous phase. In our research, nanoemulsion have been developed for Cyclosporine a using fractions of Sesame oil as encapsulating agent. Methods: The comparison between oil fractions (SOC; SOAM) and Sesame oil have been well proved through Spectral studies like FT-IR, GC-MS and rheology studies. Nanoemulsions have been developed using a modified solvent-evaporation method. FT-IR of oil fraction also shows absence of peaks showing peptide fragments, indicating its encapsulation inside oil fraction. Conclusion: The zeta potential of our selected formulation FSC2 among FSC1-FSC12 has been found to be $-15 \mathrm{mV}$, while its polydispersity is 0.325 . The in vitro studies clearly reveals first order release mechanism as best fit model for selected formulation. The $r^{2}$ for selected formulation has been identified to be 0.99 . The t80 of FSC2 has been found to be $6.5 \mathrm{Hrs}$. The TEM Studies of formulation reveal spherical appearance of particles with average particle size between $50-220 \mathrm{~nm}$.
\end{abstract}

Key words: Cyclosporine A, Nanoemulsions, Sesame oil, Biolipid, GCMS, IR.

\section{INTRODUCTION}

Cyclosporine as a peptide, is used variedly for its immunomodulatory and anti-inflammatory effects. Cyclosporine is a strong immune-suppressor, possess calcineurin inhibitory effect and inhibits apoptosis. Its poor solubility in water has prompted better formulation methods to enhance its effectiveness. ${ }^{1}$ Several attempts with modified approaches are under way for developing Cyclosporine loaded emulsified droplets for delivery to target organs. ${ }^{2-5}$ Cyclosporine delivery using nanosized droplets have been found to be a better option as compared to microemulsions. Microemulsions are less thermodynamically stable, having higher tendency of particle coalescence. Micro emulsions are easily unstabilized by fluctuations in storage conditions, even with existence of surfactants and co-surfactants. However, Nanoemulsions are thermodynamically stable emulsified systems, can also be said as a uniphase colloidal dispersions. Nanoemulsions offer several advantages over other dosage forms such as they are stable, most suitable for delivery of lipophilic drugs, enhances bioavailability of hydrophilic-lipophillic drugs, if used topically they are less irritant, non-toxic and can be utilized for controlled release. Liquid based nanoemulsions (w/o) have enormous advantages over other dosage forms, as they have high optical activity.

Peptide loaded nanoemulsions using food grade oils is new area of interest. With food grade oils, there is better acceptability, digestibility, better bioavailability and patient compatibility with compliance. The used oil from seeds of Sesamum indicum Linn. (Sesame oil) is also source of essential nutritional lipids. In our study, nanoemulsions
Submission Date: 28-11-2019; Revision Date: 26-12-2019; Accepted Date: 30-01-2020

DOI: 10.5530/ijper.54.2.41 Correspondence: Mr. Samir Bhargava, Assistant Professor, DIT-Faculty of Pharmacy, DIT University, Dehradun-248001, Uttarakhand, INDIA. Phone: +91353000378 E-mail: samirbhargava@ outlook.com

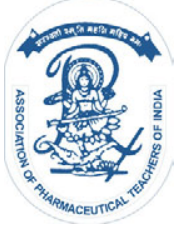

www.ijper.org 
have been developed using food grade oils fractions of Sesame oil as oily phase. The oils were further fractionated using varied solvent systems. The isolated fractions were differentiated using several spectral graphs. Nanoemulsions have been developed with isolated oil fractions using solvent emulsification method. The developed nanoemulsions have been further analyzed for Dispersibility, drug-excipient interactions and drug release studies.

\section{MATERIALS AND METHODS}

\section{Materials}

Cyclosporine A (Gift Sample-Mankind Pharma); Sesame oil (Local Supplier, Dehradun); Tween 80, Polyvinyl Alcohol (Merck India); Chloroform, Acetone, Methanol (CDH India). All other chemicals were of Analytical grade. They were used as received.

\section{Isolation of oil fractions}

Sesame oil, dissolved in Chloroform (At $4^{\circ} \mathrm{C}$ ). The solubilized oil mixture was mixed with $200 \mathrm{~mL}$ of Acetone: Methanol (1:1) solvent system. The final mixture is again kept for $24 \mathrm{hr}$ at $4^{\circ} \mathrm{C}$.

\section{FTIR of isolated lipid extracts}

The spectrometer (Shimadzu FTIR Infinity-1, Japan) fitted with DLATGS pyroelectric detector and a beam splitter of Potassium bromide has been used. The software used was IR-Solution software. These difference in spectra were recorded as \% Transmittance $(\% \mathrm{~T})$ values at each data point. ${ }^{6}$

\section{Preparation of fatty acid methyl esters for GC analysis}

The method used for formation of fatty acid methyl esters was an acid catalyzed method. ${ }^{6}$ The fatty acid transformed to its saponified derivative was investigated through GC-MS equipment (Thermo Trace 1300 GC coupled with Thermo TSQ 800 Triple Quadrupole MS; Software - Xcalibur 2.2 SP1). The Investigational conditions for GC-MS system (discussed somewhere else also) ${ }^{6}$ are as follows:- Column used - TG 5MS (30 m*0.25 mm, $0.25 \mathrm{~mm}$; Thermo Fisher Scientific, USA). Carrier gas flow rate- $1 \mathrm{~mL} / \mathrm{min}$. The results were compared by using NIST/EPA/NIH Mass Spectral Library (NIST 08) and NIST Mass Spectral Search Program (Version2.0f). However, the differences in composition of oil and its fractions (SO, SOC, SOAM) are represented in Table 1.

\section{Rheology behaviour of oils using Rheometer}

Rheology measurements was performed using a Anton Paar MCR 72 rheometer, kept at constant temperature of $2{ }^{\circ} \mathrm{C}$. Chloroform (1:9) was used for diluting oil and its fractions for rheological analysis. The rheological analysis of chloroform was initiated, with measurement of shear stress and viscosity at changeable shear rate from $0 \mathrm{~s}-1$ to $100 \mathrm{~s}-1$ in $10 \mathrm{~min}$. The graphs of shear stress vs. shear rate curve and viscosity vs. shear rate are plotted and reported.

\section{Cyclosporine A loaded Nanoemulsions Formulation development}

The Cyclosporine A loaded nanoemulsions have been prepared by modified solvent emulsification-evaporation method. ${ }^{2}$ In our method the concentration of peptide was constant while lipid concentration was varied. Hence, formulations were developed using $0.5 \%, 1 \%, 2 \%, 4 \%, 8 \%$ and $10 \%$ of oily phase which was dissolved in Chloroform and Acetone:Methanol respectively. Cyclosporine A $(2 \mathrm{mg})$ as peptide drug was added to lipid phase, followed by heating to $15^{\circ} \mathrm{C}$ for miscibility. Optimized quantities of Tween 80, Dextran (12 mg) and Poly Vinyl Alcohol was added to water as in Table 2 and 3. The lipid phase was kept in a bathsonicator (Sonication - 2-cycles, 1 cycle every $6 \mathrm{~min}$ ), followed by drop by drop addition of aqueous phase to this organic phase. Sonication resulted in formation of clear, transparent and thermodynamically stable emulsion prepared from isolated bio-lipid fractions and stored at $25^{\circ} \mathrm{C}$ in dark.

\section{FTIR of Cyclosporine A loaded nanoemulsions}

The aqueous Nanoemulsions formulations were dried for forming a film over glass slide and analyzed using ATR Technique (SAIF Punjab University, Chandigarh). These were necessary for analyzing excipient.

\section{Encapsulation efficiency of Nanoemulsions}

Cyclosporine A loaded nanoemulsions $(300 \mu \mathrm{L})$ diluted to $30 \mathrm{~mL}$ with double distilled water. The diluted nanoemulsions were centrifuged at $5000 \mathrm{rpm}$ for $5 \mathrm{~min}$. The unincorporated drug was measured in supernatant fluid by taking absorbance at $205 \mathrm{~nm}$ against Blank. A standard curve of Cyclosporine A with different concentrations was also prepared in Methanol at $205 \mathrm{~nm}^{7}$ The encapsulation has been studied by deducting free peptide from total peptide taken. This experiment was performed in triplicate and average recorded. 


\begin{tabular}{|c|c|c|c|c|c|c|}
\hline \multirow[t]{2}{*}{ Name of Compound } & \multicolumn{2}{|c|}{ Sesame Oil (SO) } & \multicolumn{2}{|c|}{$\begin{array}{l}\text { Sesame Oil- } \\
\text { Chloroform fraction } \\
\text { (SOC) }\end{array}$} & \multicolumn{2}{|c|}{$\begin{array}{l}\text { Sesame Oil - } \\
\text { Acetone:Methanol fraction } \\
\text { (SOAM) }\end{array}$} \\
\hline & RT & Peak Area & RT & Peak Area & RT & Peak Area \\
\hline - 1-Hexadecanol & 11.17 & 0.65 & - & - & - & - \\
\hline - $\quad$ E-15-Heptadecenal & 12.67 & 0.78 & - & - & - & - \\
\hline - Hexadecanoic acid, methyl ester & 13.62 & 21.94 & 13.62 & 20.03 & 13.89 & 18.76 \\
\hline - 1-Heneicosanol & 14.04 & 0.59 & - & - & - & - \\
\hline $\begin{array}{l}\text { - 9,12-Octadecadienoic acid (Z,Z)-, } \\
\text { methyl ester }\end{array}$ & 14.75 & 72.35 & 14.75 & 18.72 & 15.04 & 73.10 \\
\hline - $\quad$ Methyl stearate & 14.91 & 2.75 & 14.94 & 8.80 & 15.19 & 2.87 \\
\hline $\begin{array}{l}\text { Oleic acid, (2,2-dimethyl-1,3- } \\
\text { dioxolan-4-yl) methyl ester }\end{array}$ & 18.03 & 0.94 & - & - & - & - \\
\hline $\begin{array}{l}\text { - Phenol, 2,4-bis (1,1-dimethyl } \\
\text { ethyl)- }\end{array}$ & - & - & - & - & 10.78 & 0.65 \\
\hline - 6-Octadecenoic acid & - & - & - & - & 15.31 & 2.03 \\
\hline $\begin{array}{l}\text { 9-Octadecenethioic acid, } \\
\text { 12-hydroxy-, S-t-butyl ester }\end{array}$ & - & - & - & - & 16.76 & 1.33 \\
\hline $\begin{array}{l}\text { 9,12-Octadecadienoic } \\
\text { acid (Z,Z)-, 2,3-dihydroxypropyl } \\
\text { ester }\end{array}$ & - & - & - & - & 18.89 & 1.27 \\
\hline $\begin{array}{l}\text { 9-Octadecenoic acid (Z)-, methyl } \\
\text { ester }\end{array}$ & - & - & 14.86 & 16.05 & - & - \\
\hline $\begin{array}{l}\text { 4-(7-Allyl-7-hydroxy-2,2-dimethyl } \\
\text { tetrahydro[1,3] dioxolo [4,5-c] } \\
\text { Pyran-4-yl)3-methylbut-2-enoic } \\
\text { acid, methyl ester }\end{array}$ & - & - & 16.54 & 6.29 & - & - \\
\hline - Z-5-Methyl-6-heneicosen-11-one & - & - & 17.03 & 24.83 & - & - \\
\hline $\begin{array}{l}\text { - Oleic acid, (2,2-dimethyl-1,3- } \\
\text { dioxolan-4-yl) methyl ester }\end{array}$ & - & - & 18.05 & 5.27 & - & - \\
\hline
\end{tabular}

\begin{tabular}{|c|c|c|c|c|c|c|c|}
\hline \multicolumn{2}{|c|}{ Table 2: Preparation of Nanoemulsions using Sesame oil - Chloroform (SOC) fraction Density - 0.94 gm/mL. } \\
\hline S.No. & Formula & $\begin{array}{c}\text { FSC1 } \\
(\mathbf{1}: \mathbf{0 . 5})\end{array}$ & $\begin{array}{c}\text { FSC2 } \\
\mathbf{( 1 : 1 )}\end{array}$ & $\begin{array}{c}\text { FSC3 } \\
\mathbf{( 1 : 2 )}\end{array}$ & $\begin{array}{c}\text { FSC4 } \\
\mathbf{( 1 : 4 )}\end{array}$ & $\begin{array}{c}\text { FSC5 } \\
(\mathbf{1}: 8)\end{array}$ & $\begin{array}{c}\text { FSC6 } \\
(\mathbf{1}: 10)\end{array}$ \\
\hline 1 & Cyclosporine A $(\mathrm{mg})$ & 2 & 2 & 2 & 2 & 2 & 2 \\
\hline 2 & Tween $80(\mu \mathrm{L})-0.5 \%$ & 500 & 500 & 500 & 500 & 500 & 500 \\
\hline 3 & PVA $(\mu \mathrm{l})-0.5 \%$ & 400 & 400 & 400 & 400 & 400 & 400 \\
\hline 4 & Sesamum indicum oil fraction $(\mu \mathrm{L})$ & 1.1 & 2.1 & 4.3 & 8.5 & 17.0 & 21.3 \\
\hline 5 & Dextran $\mathrm{mg}$ & 12 & 12 & 12 & 12 & 12 & 12 \\
\hline 6 & Distilled water $(\mathrm{mL})$ q.s. & 10 & 10 & 10 & 10 & 10 & 10 \\
\hline
\end{tabular}

\begin{tabular}{|c|c|c|c|c|c|c|c|}
\hline S.No. & Formula & $\begin{array}{c}\text { FSC1 } \\
(1: 0.5)\end{array}$ & $\begin{array}{c}\text { FSC2 } \\
(1: 1)\end{array}$ & $\begin{array}{c}\text { FSC3 } \\
(1: 2)\end{array}$ & $\begin{array}{c}\text { FSC4 } \\
(1: 4)\end{array}$ & $\begin{array}{c}\text { FSC5 } \\
(1: 8)\end{array}$ & $\begin{array}{l}\text { FSC6 } \\
(1: 10)\end{array}$ \\
\hline 1 & Cyclosporine A (mg) & 2 & 2 & 2 & 2 & 2 & 2 \\
\hline 2 & Tween $80(\mu \mathrm{L})-0.5 \%(w / v)$ & 500 & 500 & 500 & 500 & 500 & 500 \\
\hline 3 & PVA $(\mu \mathrm{l})-0.5 \%(\mathrm{w} / \mathrm{v})$ & 400 & 400 & 400 & 400 & 400 & 400 \\
\hline 4 & Sesamum indicum oil fraction $(\mu \mathrm{L})$ & 1.1 & 2.2 & 4.4 & 8.9 & 17.8 & 22.2 \\
\hline 5 & Dextran mg & 12 & 12 & 12 & 12 & 12 & 12 \\
\hline 6 & Distilled water $(\mathrm{mL})$ q.s. & 10 & 10 & 10 & 10 & 10 & 10 \\
\hline
\end{tabular}


The percentage drug content estimated is analyzed using following formula -

$$
\begin{gathered}
{[\text { Total drug }-} \\
\% \text { Drug Loading Efficiency }=\frac{\text { Free drug in supernatant }]}{\text { Total drug }} \times 100
\end{gathered}
$$

\section{Particle size distribution, Polydispersity and Zeta potential of developed formulations}

The average particle size, Zeta potential and polydispersity of stable formulations has been determined using Zetasizer Nano ZS (Malvern Instruments, Malvern, UK). The average particle size and polydispersity index (PI) of lipid bio carriers have been estimated at $25^{\circ} \mathrm{C}$. Surface charge measurements have been performed using dip cell, where diluted samples are kept in capillary measurement cell and cell position was adjusted.

\section{In vitro drug diffusion studies}

The in-vitro diffusion studies has been completed using modified MS Diffusion cell as done earlier also. ${ }^{8}$ The method required donor compartment was placed over the receiving compartment, separated by a hen egg shell membrane. The formulation +in donor compartment release with time in receiving compartment containing Phsophate buffer $\mathrm{pH}$ 7.4. The complete replacement of receiver compartment filled with fresh Buffer was performed at $10 \mathrm{~min}, 1 \mathrm{Hr}, 2 \mathrm{Hr}, 4 \mathrm{Hr}, 6 \mathrm{Hr}$ and $24 \mathrm{Hr}$. The study was carried at $37 \pm 2^{\circ} \mathrm{C}$; stirring at $100 \mathrm{rpm}$. The collected sample aliquots have been analysed immediately at wavelength of $281 \mathrm{~nm}$ for Cyclosporine A. The data obtained (Table 5) from the in vitro diffusion studies have been fitted to kinetic equations using DD Solver 1.0.

\section{TEM Studies of developed nanoemulsions}

TEM studies have been performed using JEOL HRTEM (Model-JEM 2100). TEM has been performed by placing negatively stained drop over copper grid, while resolution is completed at magnification of $50000 \mathrm{X}-$ 200000X and voltage of $200 \mathrm{~V}$.

\section{Stability studies}

Different accelerated conditions have been used $\left(25 \pm 2^{\circ} \mathrm{C}\right.$ at $60 \% \mathrm{RH}, 40 \pm 2^{\circ} \mathrm{C}$ at $75 \% \mathrm{RH}$ and $\left.5 \pm 2^{\circ} \mathrm{C}\right)$ to determine stability in terms of clarity and dispersibility in lipid bio carriers. Clarity test was was carried against dark and white background to observe precipitates and foreign particles in developed aqueous formulations. For dispersibility $100 \mu \mathrm{L}$ of the liquid biocarrier system was added to $5 \mathrm{~mL}$ of water without shaking. The solubility was observed against a dark background.

\section{RESULTS AND DISCUSSION}

Cyclosporine A loaded with nanoemulsions, using food grade oils resulted in stable nanoemulsion. Twelve formulations FSC1 - FSC6 (From Chloroform fraction of Sesame oil-SOC) and FSC7-FSC12 (From Acetone: Methanol fraction of Sesame oil-SOAM) have been formulated.

Lipid fractions from Sesame oil have been isolated based on a temperature-based method. The yield of SOC fraction was $90.2 \%$, while that of SOAM was $5.16 \%$. At low temperature solubility of lipid decreased, resulting in fractionation based on solvent system used. Hence, fraction of oil separated in Acetone: Methanol fraction, while its major fraction remained in Chloroform solvent. The difference between isolated biolipids SOC; SOAM have been distinguished from main Sesame oil (SO) by several spectral and rheological studies.

\section{Spectral analysis of isolated biolipids (SOC; SOAM) and Sesame oil (SO)}

GC MS analysis of Sesame oil and isolated fractions (Figure 1) shows Hexadecanoic acid, methyl ester, (9,12-Octadecadienoic acid (Z,Z)-, methyl ester) and Methyl stearate at and near Retention times of 13.6, 14.8 and 14.9. Hence, all isolated fractions are from Sesame oil only, while differences in composition has caused mild shifts in Retention times. Some compounds like 9,12-Octadecadienoic acid (Z,Z)-, methyl ester $(72.35 \%)$ and Hexadecanoic acid, methyl ester $(21.94 \%)$ have maximum peak area in GC spectra of Sesame oil. The compounds Z-5-Methyl-6-heneicosen-11-one and 1,3-Dioxolo[4,5-c]pyran,tetrahydro-,7-(2-acetoxyethyl)7-hydroxy-2,2-dimethyl-4-(3-methoxycar bonyl-2-methylallyl)- shows peak area of 24.83 at Retention time of 17.03 with (SOC) fraction. Similarly, 9, 12-Octadecadienoic acid (Z,Z), methyl ester $(73.10 \%)$ and Hexadecanoic acid, methyl ester (18.76\%) displays maximum peak area in GC spectra of SOAM fraction.

\section{Rheology differences between Sesame oil and isolated fractions (SOC; SOAM)}

It is clearly observed from (Figure 2), difference in shear stress is proficient only with increasing shear rates. This compares the Sesame oil, isolated fractions (SOC; SOAM) and diluent used (Chloroform). The graph clearly shows that Non-newtonian shear thinning is observed with oil fractions and Sesame oil. It can be concluded for SOC, there is dip in shear rate of $11.2(1 / \mathrm{s})$ with increasing shear rate. This also suggests that further rise in shear rate is indicative of mild shear thickening effects. Also, for isolated fractions (SOC; SOAM) the shear rate slightly rises followed by 


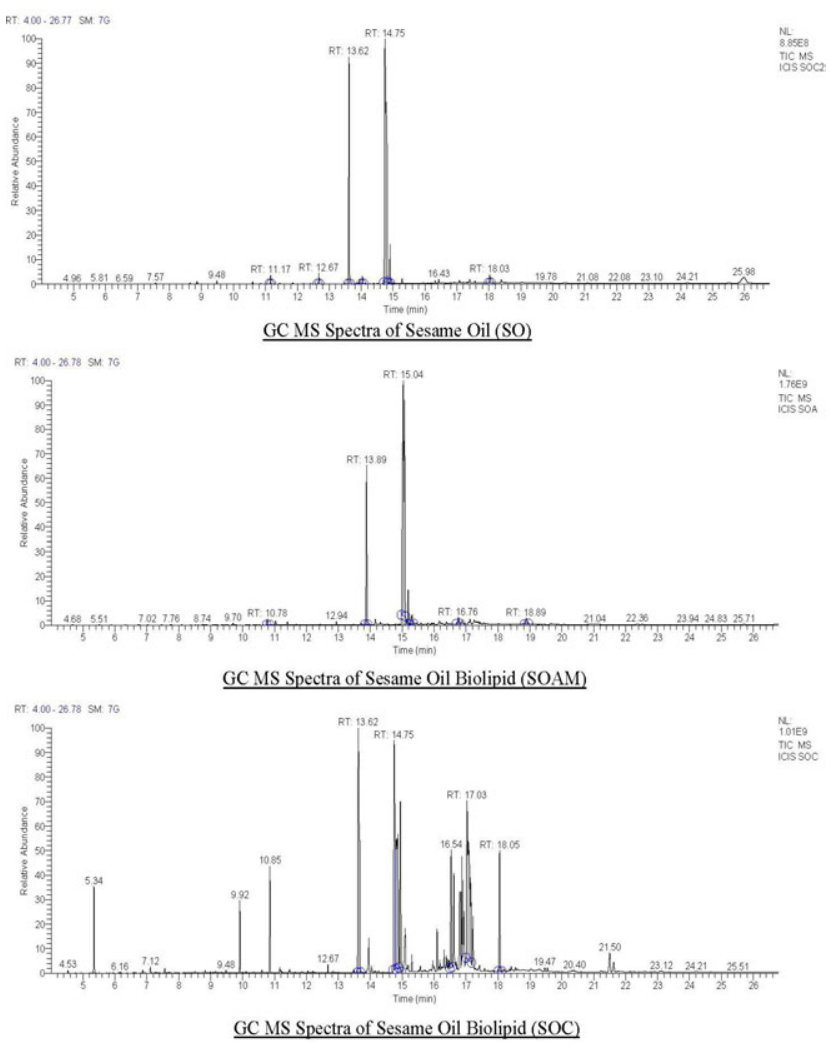

Figure 1: GC Spectra of Sesame oil and biolipid.

dynamic changes revealing complete Non-Newtonian behavior. The effect shown by SOAM is equivalent to Bingham pseudo plastic effect. The yield stress is lowest for SOAM, while it is highest for SO. The (Figure 2) clearly depicts the effect of increasing shear stress on $\mathrm{SO}$ and its fractions. Viscosity (Figure 3) reduces for all oils at shear rate of $11.2(1 / \mathrm{s})$. It takes a strong dip for SOC and then increases to prove its Non-Newtonian effect. The rheological behavior of fractions (SOC; SOAM) confirms unique blend of their biochemical composition, which is in in turn is also confirmed by its FTIR spectra.

\section{IR Spectral study of isolated oils and its fractions}

IR Spectral study (Figure 4) was performed for Sesame oil fractions (SOC; SOAM) and Sesame oil (SO). The IR spectras were overlaid in order to identify the unique functional groups present in fractions; which is necessary to compare them with Sesame oil (SO). The spectra revealed that SOC fraction, comprised of peaks 2855.73 $\mathrm{cm}^{-1} ; 1747.58 \mathrm{~cm}^{-1} ; 1447.64 \mathrm{~cm}^{-1} ; 1437.99 \mathrm{~cm}^{-1} ; 1417.74$ $\mathrm{cm}^{-1} ; 1378.2 ; 1363.73 \mathrm{~cm}^{-1} ; 1355.05 \mathrm{~cm}^{-1} ; 1340.58 \mathrm{~cm}^{-1}$; $1319.37 \mathrm{~cm}^{-1} ; 1238.25 \mathrm{~cm}^{-1} ; 1163.13 \mathrm{~cm}^{-1} ; 1119.73$ $\mathrm{cm}^{-1} ; 1099.47 \mathrm{~cm}^{-1} ; 987.6 \mathrm{~cm}^{-1} ; 970.24 \mathrm{~cm}^{-1} ; 763.84$ $\mathrm{cm}^{-1}$. Similarly IR spectra of SOAM fraction (Figure 4), shows several peaks $3010.05 \mathrm{~cm}^{-1} ; 2954.11 \mathrm{~cm}^{-1}$;

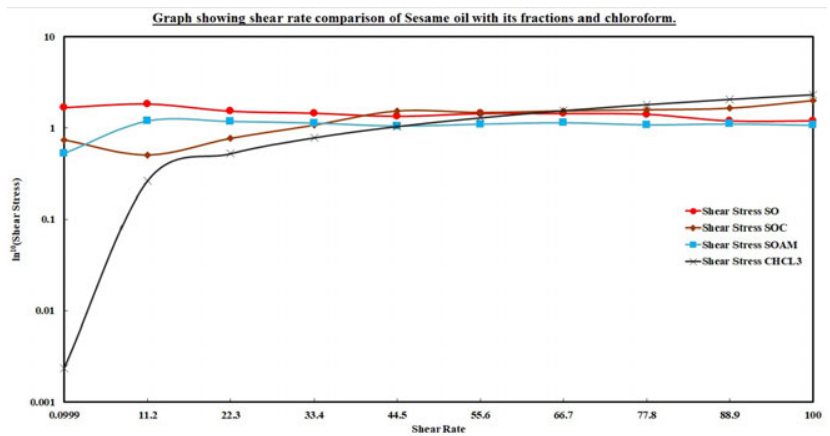

Figure 2: Graph showing shear rate comparison of Sesame oil with its fractions and chloroform.

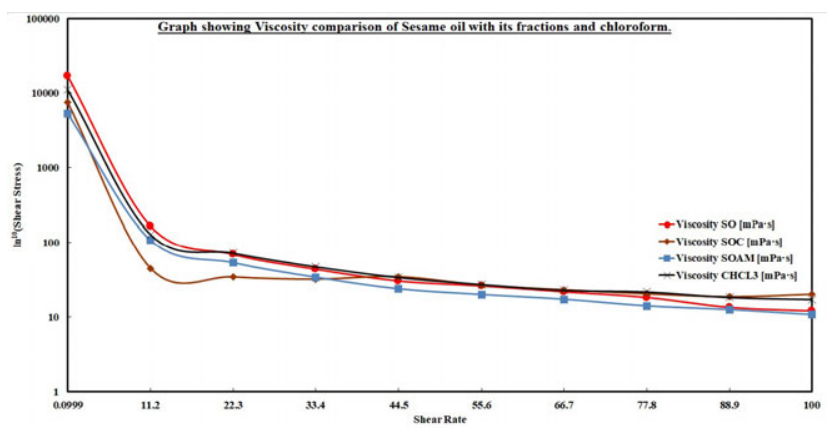

Figure 3: Graph showing Viscosity comparison of Sesame oil with its fractions and chloroform.

$2855.73 \mathrm{~cm}^{-1} ; 1739.87 \mathrm{~cm}^{-1} ; 1447.64 \mathrm{~cm}^{-1} ; 1418.71 \mathrm{~cm}^{-1}$; $1339.62 \mathrm{~cm}^{-1} ; 1238.35 \mathrm{~cm}^{-1} ; 1165.05 \mathrm{~cm}^{-1} ; 1099.47 \mathrm{~cm}^{-1}$; $720.44 \mathrm{~cm}^{-1}$. However, IR spectra of parent Sesame oil (SO) comprised of peaks such as $2925.17 \mathrm{~cm}^{-1}$; $1747.58 \mathrm{~cm}^{-1} ; 1464.03 \mathrm{~cm}^{-1} ; 1456.32 \mathrm{~cm}^{-1} ; 1447.64 \mathrm{~cm}^{-1}$; $1276.9 \mathrm{~cm}^{-1} ; 1238.35 \mathrm{~cm}^{-1} ; 1218.5 \mathrm{~cm}^{-1} ; 1203.63 \mathrm{~cm}^{-1}$; $1118.7 \mathrm{~cm}^{-1} ; 1099.47 \mathrm{~cm}^{-1} ; 1066.68 \mathrm{~cm}^{-1} ; 1031.96 \mathrm{~cm}^{-1}$. IR Spectroscopy was necessary for determining important functional groups in lipids and variation created in groups after fractionation. Also, presence of peaks $1099.47 \mathrm{~cm}^{-1}, 1447.64 \mathrm{~cm}^{-1}$ and $1238.35 \mathrm{~cm}^{-1}$ proves that fractional biolipid isolates are from Sesame oil only. Hence, these IR peaks are common in Sesame oil and biolipid isolates. The SOC biolipid from Chloroform fraction has mostly Aromatics and alkenes, which are absent in parent oil (SO). Similarly some of the IR groups represented by several peaks are present only in Acetone: Methanol biolipid of Sesame oil (SOAM), such as $\mathrm{C}-\mathrm{H}$ bonding of Halides and several Aromatics. This proves that isolated biolipids are dissimilar to parent oil ie Sesame Oil (SO).

\section{IR Spectral study of Cyclosporine A}

Cyclosporine A, being a cyclic peptide has wide array of functional groups shown by different peak frequencies in IR Region (Figure 5). The IR Spectra of Cyclosporine 


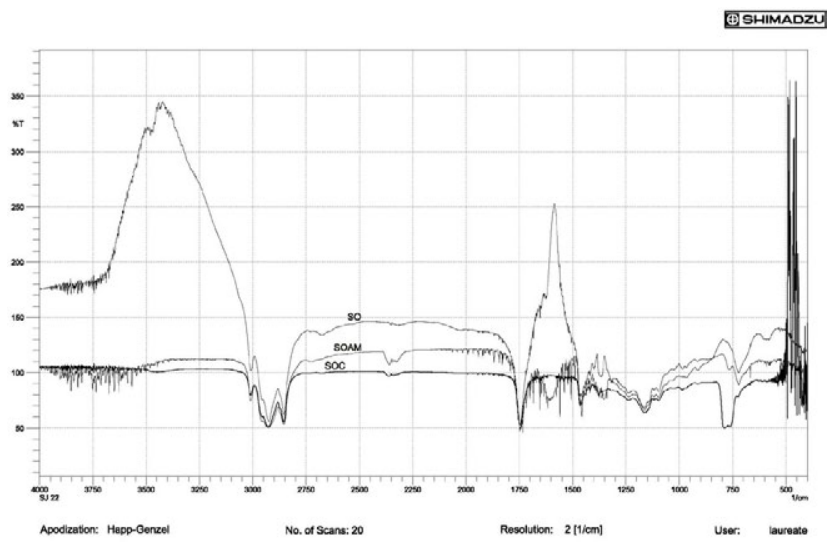

Figure 4: IR Spectra of Sesame oil SO and Biolipids SOC and SOAM.

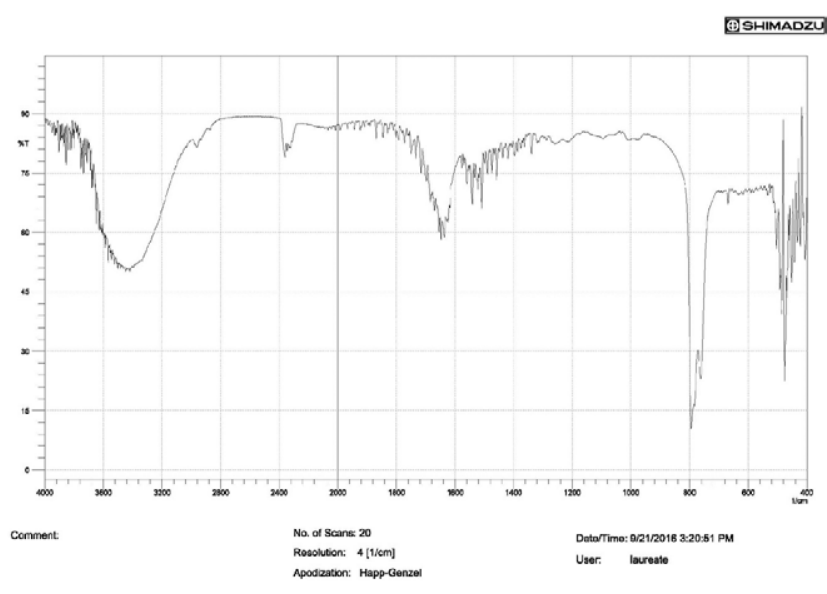

Figure 5: IR Spectra of Cyclosporine A.

A showed peaks representing $-\mathrm{NH}$ Stretching; $-\mathrm{OH}$ Stretching; $=\mathrm{CH}$ stretching; $-\mathrm{CH}_{2}$ Stretching; $-\mathrm{C}=\mathrm{O}$ Stretching; $-\mathrm{C}=\mathrm{C}$ Stretching (Aromatics); $-\mathrm{CH}_{3},-\mathrm{CH}_{2}$ Stretching of Alkanes; -C-S Stretching; -S-S Stretching. The determination of these peaks supports the interaction efficiency of peptide, where they can be deformed for better interface.

\section{\% Entrapment efficiency}

The entrapment efficiency of formulation (FSC1-FSC6) developed using biolipid SOC was in range of $25 \pm 3 \%$ to $85 \pm 2 \%$. Similarly, entrapment efficiency of formulations (FSC7-FSC12) from biolipid SOAM was in range of $04 \pm 24 \%$ to $25 \pm 2 \%$. The variation in entrapment efficiency exists due to bio-lipid used in formulation development from minimum concentration to maximum. However, optimum concentration of lipids for a formulation depends on its composition and interacting functional groups. The optimum concentration of biolipid for peptide encapsulation, slowly releases peptide through layers or voids of

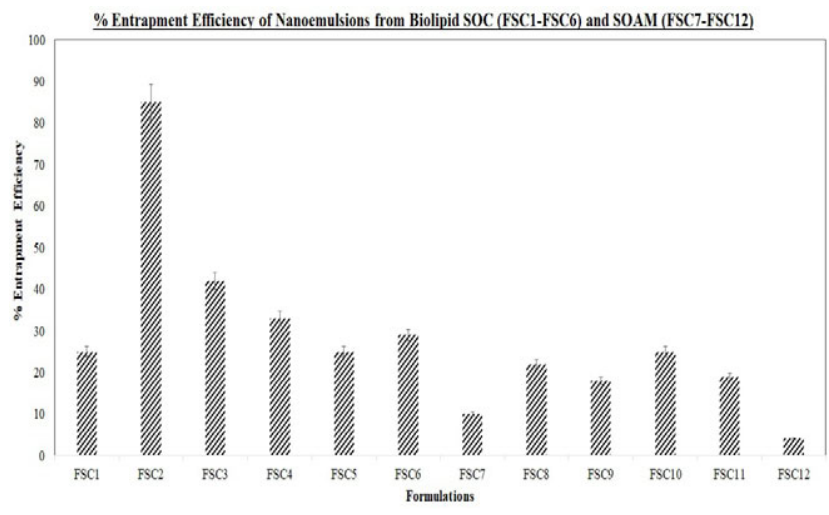

Figure 6: Graph showing \% Entrapment Efficiency of Nanoemulsions from biolipid SOC (FSC1-FSC6) and SOAM (FSC7-FSC12).

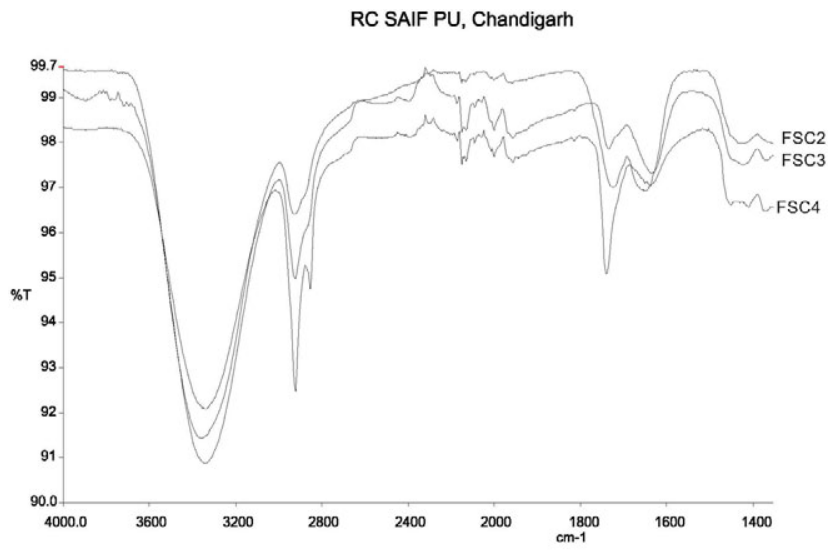

Figure 7: IR Spectra of formulations from SOC biolipid fraction.

membrane. Moreover, rapid release of peptide may be due to poor entrapment and its absorption of peptide within rapidly eroding outer lipid layers instead of inner core. It is very clear that higher or lower concentration of biolipid has destabilized the system, causing cracking and early release (Figure 6). Hence, release was mostly dependent on lipid concentration with erosion and burst effect being time-dependent.

\section{IR Spectral study of Formulations (FSC1-FSC12)}

The IR spectral study of stable formulations (FSC2; FSC3; FSC4; FSC7; FSC10) - Figure 7 and Figure 8 have been done to ensure encapsulation of peptide within core membrane. The overlaid IR Spectra of formulations FSC2; FSC3; FSC4 clearly reveals significant encapsulation of Cyclosporine A. The IR Spectra of FSC2 (Figure 7) has functional groups at $-3362.43 \mathrm{~cm}^{-1}$; $2924.85 \mathrm{~cm}^{-1} ; 1724.58 \mathrm{~cm}^{-1} ; 1649.17 \mathrm{~cm}^{-1} ; 1245.89 \mathrm{~cm}^{-1}$; $1078.52 \mathrm{~cm}^{-1} ; 1034.98 \mathrm{~cm}^{-1}$. IR Spectra of formulation FSC3 (Figure 7) has functional groups at $-3339.12 \mathrm{~cm}^{-1}$; $2927.29 \mathrm{~cm}^{-1} ; 1637.87 \mathrm{~cm}^{-1} ; 1427.9 \mathrm{~cm}^{-1} ; 1032.87 \mathrm{~cm}^{-1}$. 


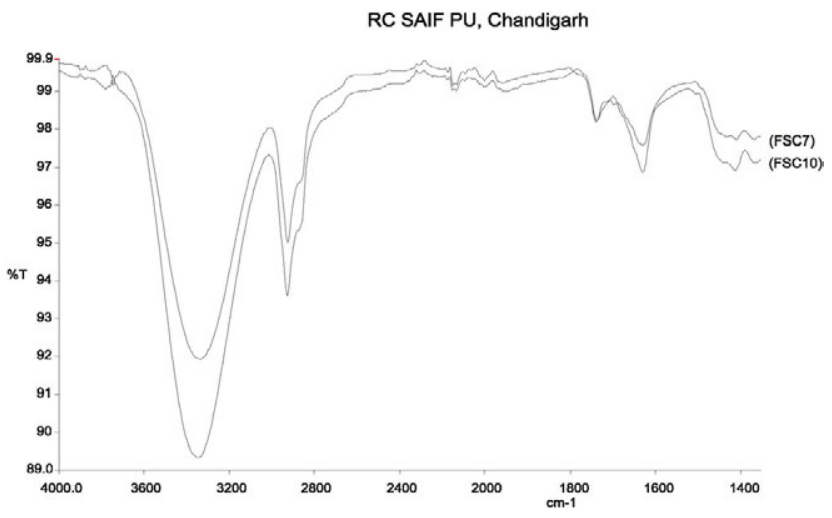

Figure 8: IR Spectra of formulations from SOAM biolipid fraction.

IR Spectra of formulation FSC4 (Figure 7) has functional groups at $-3338.6 \mathrm{~cm}^{-1} ; 2926.46 \mathrm{~cm}^{-1} ; 2155.27 \mathrm{~cm}^{-1}$; $1741.22 \mathrm{~cm}^{-1} ; 1369.98 \mathrm{~cm}^{-1} ; 1079.42 \mathrm{~cm}^{-1} ; 1027.12 \mathrm{~cm}^{-1}$. The overlaid IR Spectra of formulations FSC7; FSC10 (Figure 8) also shows significant encapsulation of Cyclosporine A. The IR Spectra of FSC7 (Figure 8) has functional groups at $3337.67 \mathrm{~cm}^{-1} ; 2927.37 \mathrm{~cm}^{-1}$; $1738.32 \mathrm{~cm}^{-1} ; 1633.02 \mathrm{~cm}^{-1} ; 1412.61 \mathrm{~cm}^{-1} ; 1079.52 \mathrm{~cm}^{-1}$; $1028.49 \mathrm{~cm}^{-1}$. IR Spectra of formulation FSC10 (Figure 8) has functional groups at $3334.75 \mathrm{~cm}^{-1} ; 2925.68$ $\mathrm{cm}^{-1} ; 2856.98 \mathrm{~cm}^{-1} ; 1740.91 \mathrm{~cm}^{-1} ; 1626.82 \mathrm{~cm}^{-1} ; 1369.77$ $\mathrm{cm}^{-1} ; 1247.58 \mathrm{~cm}^{-1} ; 1147.76 \mathrm{~cm}^{-1} ; 1079.18 \mathrm{~cm}^{-1} ; 1024.94$ $\mathrm{cm}^{-1} ; 934.36 \mathrm{~cm}^{-1} ; 850.76 \mathrm{~cm}^{-1} ; 709.37 \mathrm{~cm}^{-1}$. Spectral study of stable formulations (FSC2; FSC3; FSC4; FSC7; FSC10)- Figure 7 and Figure 8 clearly showed that peaks at $3362.43 \mathrm{~cm}^{-1}, 3339.12 \mathrm{~cm}^{-1}, 3338.6 \mathrm{~cm}^{-1} ; 3337.67$ $\mathrm{cm}^{-1} ; 3334.75 \mathrm{~cm}^{-1}$ are due to $-\mathrm{OH}$ Stretching. The high intensity of $-\mathrm{OH}$ stretching may be due to presence of Tween 80, Polyvinyl Alcohol, Dextrose and isolated lipids (SOC; SOAM) in the developed formulations. Moreover, it is observed that intensity of peaks increased with concentration of oils. It was also observed that prime functional groups of Cyclosporine $\mathrm{A}\left(\mathrm{C}=\mathrm{O} ; \mathrm{NH}_{2} ; \mathrm{C}-\mathrm{S}\right.$ Stretching; S-S Stretching) were absent in formulation IR spectral peak. This proved encapsulation of Cyclosporine in matrix of isolated biolipids.

\section{Particle size Distribution and polydispersity of biolipid formulations}

Particle size distribution is method for analyzing particles sizes based on size ranges. Polydispersity, a dimensionless scale defines degree of non-uniformity among particles in a colloidal dispersion. The smaller size of nanoparticles supports them for their easy capture by biological receptors, easier distribution, rapid bioavailability and enhanced targeting potential. Hence, polydispersity of our formulations have been measured using Malvern

\begin{tabular}{|c|c|c|c|c|c|c|c|c|}
\hline \multirow{2}{*}{ 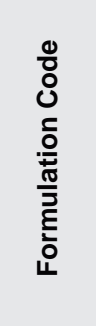 } & \multicolumn{6}{|c|}{$\frac{\frac{0}{U}}{\frac{N}{\sigma}} \frac{\stackrel{N}{\omega}}{\square}$} & \multirow{2}{*}{ 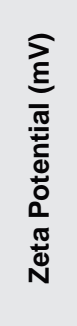 } & \multirow{2}{*}{$\begin{array}{l}\frac{\lambda}{0} \\
\frac{0}{2} \\
\frac{0}{0} \\
\frac{0}{0} \\
\frac{\lambda}{0} \\
0\end{array}$} \\
\hline & 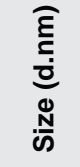 & 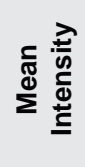 & ن & 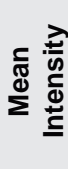 & 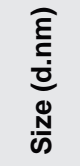 & 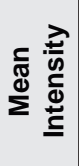 & & \\
\hline \multirow[t]{3}{*}{ FSC2 } & 91.28 & 4.4 & 105.7 & 15 & 122.4 & 22 & \multirow[t]{3}{*}{-14.6} & \multirow[t]{3}{*}{0.325} \\
\hline & 141.8 & 20.3 & 164.2 & 14.7 & 190.1 & 9.4 & & \\
\hline & 220.2 & 5.8 & & & & & & \\
\hline \multirow[t]{2}{*}{ FSC3 } & 58.7 & 28.22 & 68.06 & 31.4 & 78.82 & 18.5 & \multirow[t]{2}{*}{-28.6} & \multirow[t]{2}{*}{0.333} \\
\hline & 91.28 & 7.1 & 105.7 & 1.8 & & & & \\
\hline \multirow[t]{3}{*}{ FSC4 } & 164.2 & 3.9 & 190.1 & 12.5 & 220.1 & 19.6 & \multirow[t]{3}{*}{-16.7} & \multirow[t]{3}{*}{0.184} \\
\hline & 255 & 20.7 & 295.3 & 17.5 & 342 & 12.4 & & \\
\hline & 396.1 & 7.5 & & & & & & \\
\hline \multirow[t]{2}{*}{ FSC7 } & 220.2 & 172.2 & 255 & 20.4 & 295.3 & 18.9 & \multirow[t]{2}{*}{-19.2} & \multirow[t]{2}{*}{0.071} \\
\hline & 342 & 14.4 & 396.1 & 9.2 & 458.7 & 5.4 & & \\
\hline \multirow[t]{3}{*}{ FSC10 } & 105.7 & 10.8 & 122.4 & 21.4 & 141.8 & 23.9 & \multirow[t]{3}{*}{-14.5} & \multirow[t]{3}{*}{0.073} \\
\hline & 164.2 & 18.4 & 190.1 & 11.6 & 220.2 & 6.4 & & \\
\hline & 255 & 3.3 & & & & & & \\
\hline
\end{tabular}

Zeta sizer. The polydispersity of stable formulation FSC2, FSC3 and FSC4 developed using isolated biolipid SOC, has been found to be $0.325,0.333$ and 0.184 (Table 4) Similarly, polydispersity of stable formulations FSC7 and FSC10 from isolated biolipid SOAM, has been found to be 0.071 and 0.073 . Polydispersity Index, a measure of size distribution with values less then 0.5 indicates a monodisperse formulation. ${ }^{8}$ However, polydispersity of selected formulation FSC2 was 0.325 , indicating it to be a monodisperse system (Figure 9).

\section{Zetapotential studies of biolipid formulations}

Zeta potential, is a charge over the colloidal molecule in medium and defines the stability and shelf life of formulation. Stability of formulation easily alters with time, due to variation in contact of colloidal surface. Hence, alteration in stability may lead to flocculation within our dispersion. Zeta potential of our developed formulations FSC2, FSC3 and FSC4 from SOC biolipids is $-14.6 \mathrm{mV},-28.6 \mathrm{mV}$ and $-16.7 \mathrm{mV}$ (Table 4). However, zeta potential of formulations FSC7 and FSC10 from SOAM biolipid is $-19.2 \mathrm{mV}$ and $-14.5 \mathrm{mV}$. Formulations with zeta potential lying in range of -10 to $-30 \mathrm{mV}$ have incipient stability ie they become stable 


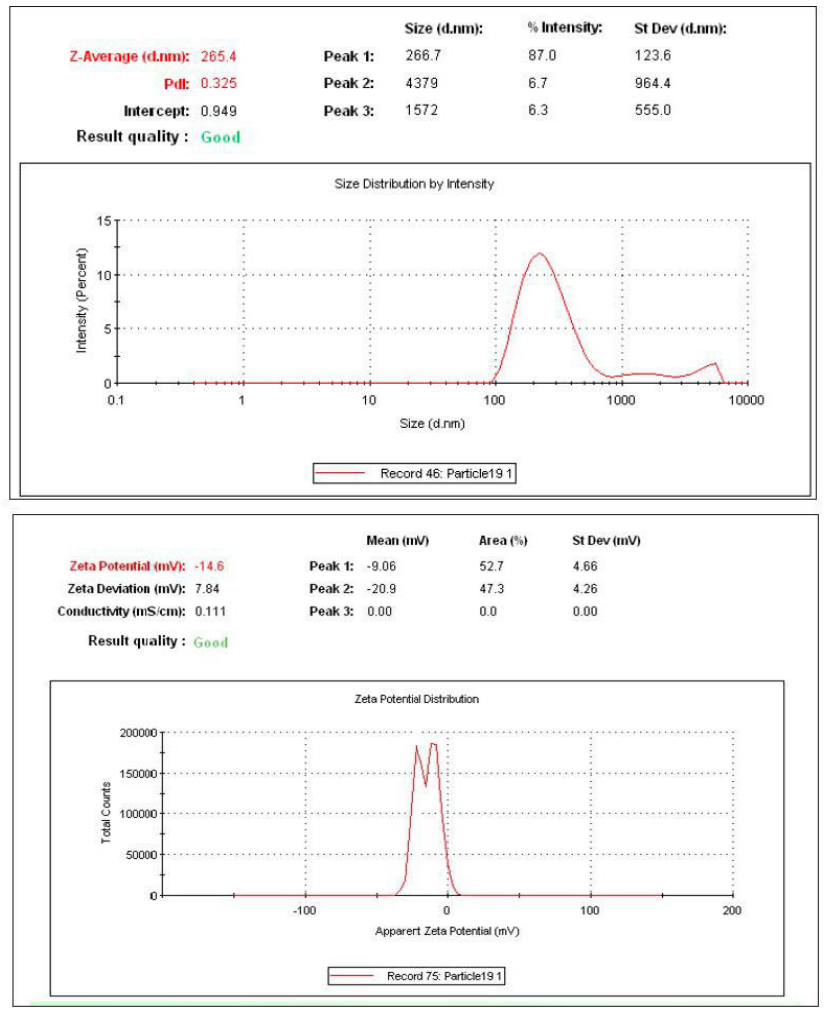

Figure 9: Particle Size Distribution and Zeta Potential of FSC2.

with time. These selected formulations showed stability with progressive time. ${ }^{9}$ Also, negatively charged zeta potential may be due to negatively charged fatty acids in bio lipid fractions. ${ }^{10}$

\section{In vitro diffusion studies of Cyclosporine loaded formulations from isolated biolipids of Sesame oil (SOC; SOAM)}

In-vitro drug diffusion studies were based on release of peptide through its core. The release data is fitted to kinetic models, where $R^{2}$ is determined to identify model with best release profile. All stable formulations were subjected to in-vitro release study except FSC10 and FSC12, due to phase separation. However, formulations FSC1 - FSC6 (Table 5; Figure 10) were prepared using biolipid fraction SOC of Sesame oil, while

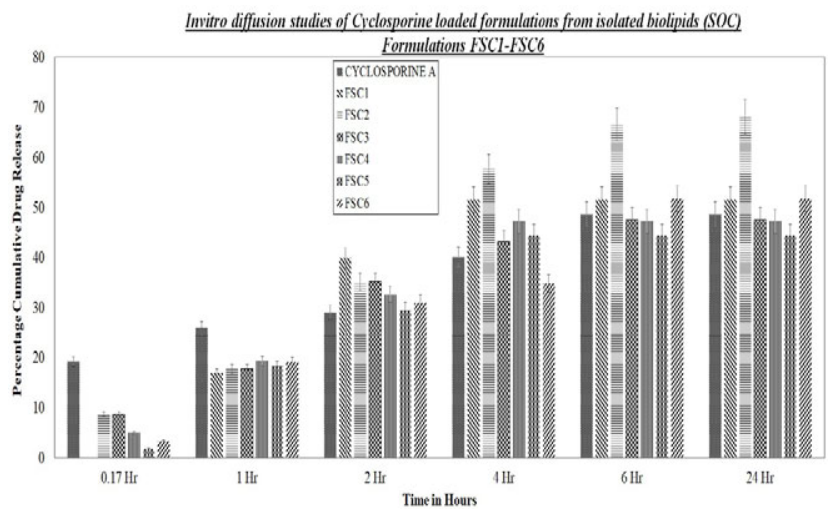

Figure 10: In vitro diffusion studies of Cyclosporine loaded formulations from isolated biolipids (SOC).

formulations FSC7-FSC12 were from biolipid fraction SOAM. The release rate of selected formulations FSC1-FSC6 based on $\mathrm{t}_{80} \%$ has been ordered as - FSC2 $>$ FSC3 > FSC4. Similarly peptide release at end of 24 Hrs from formulations FSC7-FSC12 based on $\mathrm{t}_{80} \%$ have been arranged as - FSC10 > FSC7 (Table 5; Figure 11). A graph, plotted between \% Cumulative Drug Release (CDR) and time was used for calculation of $R^{2}$ and $t_{80} \%$ values. Hence, FSC2 was selected as best formulation from formulations FSC1-FSC6 $\left(R^{2}\right.$ value of $0.99 ; \mathrm{t}_{80} \%$ value of $\left.6.2 \mathrm{Hr}\right)$. The best-fitted model for release of peptide from FSC2 (From SOC Biolipid) was First order mechanism, where drug diffusion is dependent on its concentration. The formulation FSC10 from biolipid SOAM (Formulations FSC7-FSC12) was the best formulation with $\left(R^{2}\right.$ value of $0.99 ; \mathrm{t}_{80} \%$ value of $4.39 \mathrm{Hr}$ ). The formulation followed First order mechanism. Hence, based on release formulation and $\%$ entrapment efficiency FSC2 from SOC biolipid was selected as best formulation system.

\section{Stability studies}

Stability studies represented no change in dispersibility, release and clarity for formulations. All optimized formulations showed acceptable drug release after stability studies. Hence, there was no deterioration of peptide as estimated after release study from UV Spectra.

Table 5: Release rate kinetics of formulations of best stable formulations from FSC1-FSC12.

\begin{tabular}{|c|c|c|c|c|c|c|c|c|c|}
\hline \multirow{2}{*}{$\begin{array}{c}\text { Biolipid } \\
\text { used }\end{array}$} & $\begin{array}{c}\text { Formulation } \\
\text { Code }\end{array}$ & $\begin{array}{c}\text { Zero } \\
\text { Order } \\
\text { Model }\end{array}$ & $\begin{array}{c}\text { First } \\
\text { Order } \\
\text { Model }\end{array}$ & $\begin{array}{c}\text { Higuchi } \\
\text { Model }\end{array}$ & $\begin{array}{c}\text { Korsmeyer- } \\
\text { Peppas } \\
\text { Model }\end{array}$ & $\begin{array}{c}\text { Hixson- } \\
\text { Crowell } \\
\text { Model }\end{array}$ & \multicolumn{2}{|c|}{$\begin{array}{c}\text { Best Fit } \\
\text { Model }\end{array}$} & \multicolumn{2}{|c|}{$\begin{array}{c}\text { Release rate of Best } \\
\text { Fit model }\end{array}$} \\
\hline \multirow{2}{*}{ SOC } & FSC2 & -0.63 & 0.99 & 0.60 & 0.85 & 0.78 & First Order & 1.82 & 6.23 \\
\cline { 2 - 10 } & FSC3 & -1.35 & 0.98 & 0.34 & 0.83 & 0.51 & First Order & 1.41 & 3.26 \\
\cline { 2 - 11 } & FSC4 & -1.31 & 0.99 & 0.32 & 0.79 & 0.49 & First Order & 1.31 & 3.03 \\
\hline \multirow{2}{*}{ SOAM } & FSC7 & -0.30 & 0.98 & 0.62 & 0.77 & 0.81 & First Order & 1.51 & 4.16 \\
\cline { 2 - 11 } & FSC10 & -0.72 & 0.98 & 0.61 & 0.89 & 0.76 & First Order & 1.89 & 4.39 \\
\hline
\end{tabular}




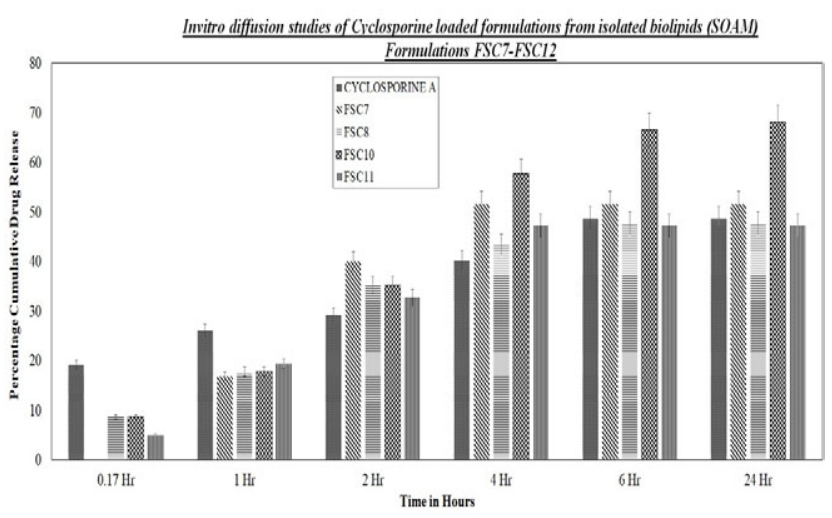

Figure 11: In vitro diffusion studies of Cyclosporine loaded formulations from isolated biolipids (SOAM).

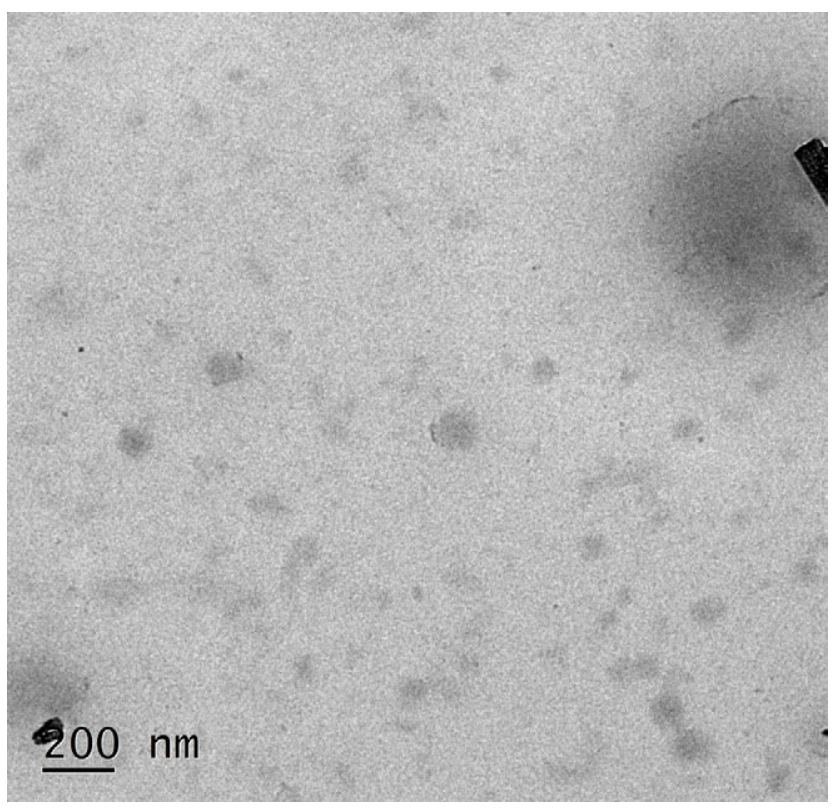

Figure 12: TEM image of FSC2.

The drug release through biolipid barriers shows sufficient residence time in their core structure, which proves adequate probability for better bioavailability of peptide through selected formulations.

\section{TEM Studies}

The TEM photographs of FSC2 (Figure 12) also shows particle size range from $50-200 \mathrm{~nm}$ as proved by data obtained from Particle size distribution analysis in Figure 9. The emulsified particles seen are spherical in shape, smooth surface and without aggregation.

\section{CONCLUSION}

In our current research, we formulated there modynamically stable cyclosporine containing nanoemulsions. The prolonged $t_{80}$ of $6.2 \mathrm{hrs}$, represents the retardibility of biolipids. Hence peptide will be released through a prolonged period of time. Moreover, the used biolipids are completely edible and safe, as they are derived from food grade oils. The application and modification of such biolipids will protect the peptides from harsh and adverse conditions of GI Tract, topical and ocular delivery platforms. Hence it was concluded that our formulation can serve as a promising approach for successful delivery of Immunosuppressive peptide by protecting it from first pass metabolism, providing high local concentration.

\section{ACKNOWLEDGEMENT}

Authors are highly thankful to Shri Anuj Agarwal Ji, Chairman DIT University, India for providing support and facilities for carrying the work. They are also thankful to STIC, Kerala, India for TEM Facility; SAIF (UCIM) Punjab University India for IR and GC-MS Facility; Laureate Institute of Pharmacy for IR Facility; Dr Ketuusetuo, Jadavpur University, India for Zetasizer Facility.

\section{CONFLICT OF INTEREST}

The authors declare no conflict of interest.

\section{ABBREVIATIONS}

SO: Sesame oil; SOC: Chloroform fraction; SOAM: Acetone Methanol fraction; FT-IR: Fourier transform - Infrared; GC-MS: Gas Chromatograph - Mass spectra; TEM: Transmission electron microscopy.

\section{REFERENCES}

1. Park CH, Kim MK, Kim EC, Kim JY, Kim TI, Kim HK, et al. Efficacy of Topical Cyclosporine Nanoemulsion 0.05\% Compared with Topical Cyclosporine Emulsion $0.05 \%$ and Diquafosol $3 \%$ in Dry Eye. Korean J Ophthalmol. 2019;33(4):343-52.

2. Yadav S, Gattacceca F, Panicucci R, Amiji MM. Comparative Biodistribution and Pharmacokinetic Analysis of Cyclosporine: A in the Brain upon Intranasal or Intravenous Administration in an Oil-in-Water Nanoemulsion Formulation. Mol Pharm. 2015;12(5):1523-33.

3. Akhter S, Anwar M, Siddiqui MA, Ahmad I, Ahmad J, Ahmad MZ, et al. Improving the topical ocular pharmacokinetics of an immunosuppressant agent with mucoadhesive nanoemulsions: Formulation development, in-vitro and in-vivo studies. Colloids Surf B Biointerfaces. 2016;148:19-29.

4. Musa SH, Basri M, Fard MHR, Shamsudin N, Salim N. Enhancement of physicochemical properties of nanocolloidal carrier loaded with cyclosporine for topical treatment of psoriasis: In vitro diffusion and in vivo hydrating action. Int J Nanomedicine. 2017;12:2427-41.

5. Alvarez-Figueroa MJ, Abarca-Riquelme JM, González-Aramundiz JV. Influence of protamine shell on nanoemulsions as a carrier for cyclosporine-A skin delivery. Pharm Dev Technol. 2019;24(5):630-8.

6. Bhargava S, Madhav NVS. Data on Spectroscopic, Rheological characterization of neem oil and its isolated fractions. Data Brief. 2018;21:996-1003.

7. Pecchio M, Salman H, Irache JM, Renedo MJ, Dios-Viéitez MC. Development and validation of a HPLC method for the determination of Cyclosporine $A$ in 
new bioadhesive nanoparticles for oral administration. Indian J Pharm Sci. 2014;76(2):132-7

8. Tyagi YT, Madhva NVS. Design of selegiline-loaded bio-nanosuspension for the management of depression using novel bio-retardant from Manilkara zapota. Drug Dev Ind Pharm. 2019;45(8):1351-60. in Nanomedicine for the Delivery of Therapeutic Nucleic Acids, United Kingdom: Elsevier. 2019;45-58.

10. Ahmad N, Ahmad R, Al-Qudaihi A, Alaseel SE, Fita IZ, Khalid MS, et al A novel self-nanoemulsifying drug delivery system for curcumin used in the treatment of wound healing and inflammation. 3 Biotech. 2019;9(10):360.

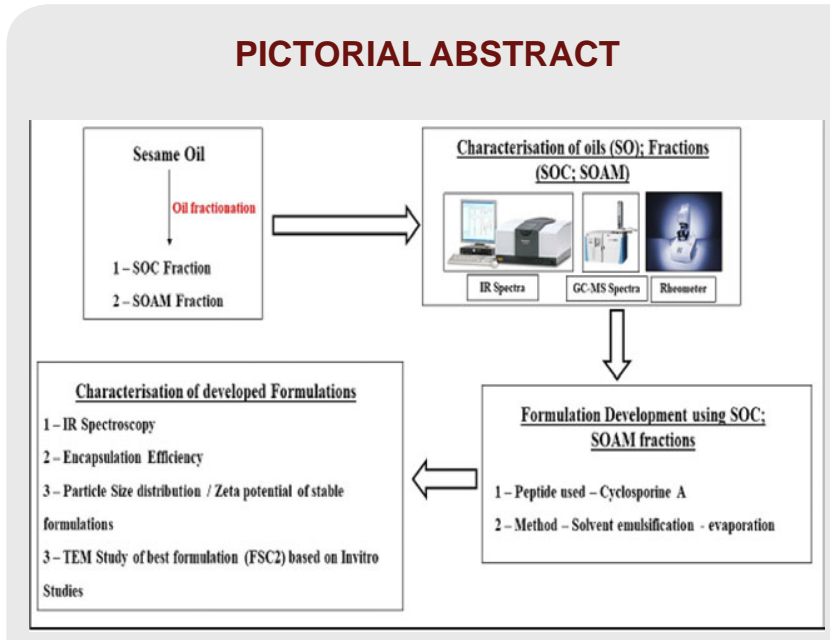

About Authors

\section{SUMMARY}

In this research, the fractions from oil have been used for encapsulating Cyclosporine A. The isolated fractions have been differentiated from native oil, using several spectral and rheological techniques like FT-IR, GC-MS and Rheometer. The peptide has been encapsulated in oil fraction, using modified solvent emulsification-evaporation technique. The ratio of oil have been varied to determine the optimum formulation. Formulations developed have been subjected to spectral studies using FT-IR, to identify proper encapsulation of peptide. Zeta potential studies and particle size distribution analysis, along with in vitro analysis proved that FSC2 as best formulation system. The TEM image of FSC2 the presence of spherical particles, with size around $200 \mathrm{~nm}$.

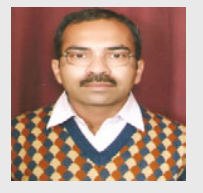

Mr. Samir Bhargava, Assistant Professor is working at DIT University since 2006 till date. He has filed 1 Indian patent, published more than 30 research papers and conference proceedings. He has received Best oral presentation Award in $24^{\text {th }}$ Annual National Convention of APTI. His area of research includes development of novel platforms for protein and peptide delivery and solid-state fermentation.

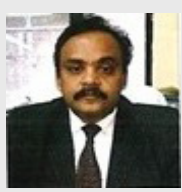

Prof. (Dr.) N. V. Satheesh Madhav, is currently working as Director DIT- Faculty of Pharmacy, DIT University from 2008 till date. He has published more than 91 research papers and has filed 86 Indian Patents on various Biopolymers and Innovative concepts on Drug Delivery Systems. He is a pioneer in exploring novel drug delivery routes across oro-transmucosal, Transliabial, Translingual, Transungual, Transnabi, Ocular to brain, Transcranial, ear to brain and oral transoft palatal drug delivery routes. He has isolated novel polymers from various natural edible sources and screened for its Pharmaceutical Applications.

Cite this article: Bhargava S, Madhav NVS. Cyclosporine A loaded Nanoemulsions using Bio-oil Fractions of Sesame Oil. Indian J of Pharmaceutical Education and Research. 2020;54(2):357-66. 